\title{
Cossos tòxics ‘ etnoepidemiologia sociocultural de la contaminació interna per compostos tòxics persistents (CTP) a Espanya
}

Eva Zafra Aparici, Universitat Rovira i Virgili, eva.zafra@urv.cat Araceli Muñoz García, Universitat Rovira i Virgili, araceli.munoz67@ub.edu Cristina Larrea Killinger, Universitat de Barcelona, larrea@ub.edu

El projecte de recerca "Cossos tòxics: etnoepidemiologia sociocultural de la contaminació interna per compostos tòxics persistents (CTP) a Espanya" és una recerca en curs, de tipus interdisciplinari (amb antropòlegs, filòsofs i epidemiòlegs), adscrita al Departament d'Antropologia Social de la Universitat de Barcelona, i que disposa del suport i el finançament del Programa Nacional de Projectes de Recerca Fonamental del Ministeri de Ciència i Innovació (CSO 2010/18661). El grup de recerca està format per la investigadora principal, la Dra. Cristina Larrea (UB); el Dr. Jaume Mascaró (UB); el Dr. Miquel Porta (UAB-IMIM); la Dra. Eva Zafra (URV); el Dr. Joan Muela (Pass International Project); la doctoranda en antropologia social Araceli Muñoz (URV), i l'estudiant de màster Arantxa Begueria (UB).

El principal objectiu és crear una línia de recerca etnoepidemiològica centrada en l'anàlisi dels discursos i les pràctiques socioculturals sobre l'experiència corporal de la contaminació humana i de la contaminació interna per compostos tòxics persistents (CTP) a Espanya.

El concepte d'etnoepidemiologia sociocultural pretén integrar les experiències de recerca d'epidemiòlegs i antropòlegs en un debat teoricometodològic en el camp d'intersecció entre l'antropologia mèdica i l'epidemiologia ambiental i social. És un intent d'integrar els avenços realitzats pels epidemiòlegs al voltant del concepte d'etnoepidemiologia i pels antropòlegs en relació amb el concepte d'epidemiologia sociocultural i epidemiologia cultural (Almeida et. al., 2012; Almeida, 2006). En aquest sentit, la recerca tracta de cercar solucions més eficients i culturalment sostenibles per abordar de manera integrada els problemes de salut que afecten els individus i la societat. 
El primer objectiu específic de la recerca és analitzar la percepció sociocultural del risc químic dels tòxics i, en particular, la dels CTP a l'Estat espanyol. Per això, es parteix de l'anàlisi de la percepció social del risc, el perill i la toxicitat, i de la relació entre els discursos socials i científics en la producció d'aquest coneixement.

Els CTP són substàncies químiques utilitzades en la producció agrícola $\mathrm{i}$ industrial que s'incrusten en petites dosis en el cos a través del consum d'aliments i de la contaminació ambiental. El seu caràcter invisible i les conseqüències que tenen a llarg termini en la salut humana estan comportant canvis en les representacions socials sobre el risc i la contaminació interna, així com nous reptes en les polítiques mediambientals i de salut pública. A més a més, es tracta d'un problema amb importants implicacions culturals i econòmiques (Porta, Puigdomènech i Ballester, 2009).

Atès que la consciència social sobre aquest tema és incipient a Espanya, el projecte també pretén difondre els resultats per contribuir a una major conscienciació del problema i col-laborar en el disseny de noves polítiques públiques que redueixin l'exposició de les persones a aquests compostos.

Finalment, el tercer objectiu que es planteja aquest grup de recerca se centra en les dimensions socioculturals de la corporalitat toxica. Concretament, en l'anàlisi dels discursos i pràctiques al voltant de la toxicitat i de la toxicitat per CTP. Sobre això, s'ha observat com la societat percep i reinterpreta els diferents discursos socials, científics i llecs existents sobre la contaminació i els tòxics. A més a més, s'ha emfatitzat en el procés interpretatiu de la introducció dels tòxics en el cos i dels perills que això representa per a la salut i s'han explorat les diferents narratives sobre la responsabilitat envers els tòxics i les possibles solucions que individualment i socialment es plantegen.

Per tal d'assolir aquests objectius, s'ha portat a terme un estudi qualitatiu que ha constat de dues fases. Actualment, s'està treballant en una tercera fase de la recerca, centrada en un estudi quantitatiu.

L'estudi qualitatiu ha constat de dues fases: la primera ha consistit en entrevistes semiestructurades a un conjunt de 10 informants, experts (metges, periodistes, advocats, arquitectes...) i pacients (SQM, fibromiàlgia i lipoatròfia semicircular), amb experiència en CTP. En la segona fase s'han realitzat un total de 43 entrevistes semiestructurades a persones que, per la seva condició laboral (agricultors, ramaders, policies, bombers, carnissers, cuiners, tècnics, 
mecànics, mestres, infermeres...) o posició ideològica (grups ecologistes, agricultura ecològica, cooperatives de producció agrícola...), estan especialment conscienciades sobre el tema dels tòxics i els seus efectes en la salut. El tipus de mostra ha estat no probabilística i propositiva, segons els paràmetres específics de l'estudi, amb la intenció de trobar la màxima variació i heterogeneïtat dels diferents sectors professionals i obtenir un mostra equilibrada amb una representació similar entre sexes, grups d'edat, nivell educatiu i àmbit geogràfic.

A partir dels primers resultats de l'estudi qualitatiu, la tercera etapa de la recerca (ara en curs) se centra en l'anàlisi de la construcció social de la confiançadesconfiança cap als aliments que deriven de la toxicitat dels CTP, partint del supòsit que la confiança constitueix una forma efectiva de comprendre la complexitat i la incertesa que els efectes dels tòxics tenen sobre la salut. ${ }^{1}$ En aquest sentit, s'està dissenyant un qüestionari quantitatiu que permeti conèixer i relacionar la confiança o desconfiança que tenen els ciutadans respecte a aquest tipus de compostos.

Els primers resultats de l'estudi qualitatiu apunten a reflexionar i discutir algunes qüestions interessants sobre les noves maneres de pensar i fer en relació amb el risc i la corporeïtat tòxica. S' ha observat que les pràctiques que la ciència i l'economia continuen exercint a l'hora de manipular la natura i les persones en nom del progrés sexpressen de manera molt complexa quan el cos ocupa el centre de producció dels discursos socials sobre la contaminació. Letnografia mostra, a més a més, com els discursos llecs i científics sobre la toxicitat del cos adquireixen una nova dimensió política i moral centrada en els efectes nocius dels tòxics sobre la salut.

\section{Bibliografia}

Almeida, N. (2006). "Complejidad y transdisciplinariedad en el campo de la salud colectiva: evaluación de conceptos y aplicaciones”, Salud Colectiva 2 (2): 123-146.

Almeida N.; Fernandes R.; Larrea-Killinger C.; Silva, L. A. V. (2012). "Construindo a Etnoepidemiologia", a: Almeida-Filho, N.; Barreto, M. (eds.). Epidemiologia E Saúde: Fundamentos, Métodos, Aplicações. Rio de Janeiro: Guanabara-Koogan, 386-394.

1 Per aprofundir en la relació entre confiança i incertesa, vegeu Luhmann (1996). 
Luhmann, N. (1996). Confianza. Barcelona: Anthropos.

Porta, M.; Puigdomènech, E.; Ballester F. (eds.) (2009). Nuestra contaminación interna. Concentraciones de compuestos tóxicos persistentes en la población española. Madrid: Los Libros de la Catarata. 